\title{
Robot-Assisted Retroperitoneal Lymphadenectomy In A Patient With Type I Papillary Renal Cancer Recurrence After Five Years Of Follow-Up: A Case Report.
}

\section{Yazan AL SALHI}

Universita degli Studi di Roma La Sapienza Facolta di Farmacia e Medicina

\section{Andrea FUSCHI}

Universita degli Studi di Roma La Sapienza Facolta di Farmacia e Medicina

Gennaro VELOTTI

Universita degli Studi di Roma La Sapienza Facolta di Farmacia e Medicina

Lorenzo CAPONE

Universita degli Studi di Roma La Sapienza Facolta di Farmacia e Medicina

\section{Sara AVERSA}

Universita degli Studi di Roma La Sapienza Facolta di Farmacia e Medicina

\section{Cosimo DE NUNZIO}

Universita degli Studi di Roma La Sapienza Facolta di Medicina e Psicologia

\section{Vincenzo PETROZZA}

Universita degli Studi di Roma La Sapienza Facolta di Farmacia e Medicina

\section{Antonio CARBONE}

Universita degli Studi di Roma La Sapienza Facolta di Farmacia e Medicina

Antonio Luigi Pastore ( $\square$ antopast@hotmail.com )

Universita degli Studi di Roma La Sapienza Facolta di Farmacia e Medicina https://orcid.org/00000003-4293-9174

\section{Case report}

Keywords: Papillary renal cell carcinoma, Type 1, recurrence, robotic surgery, long term follow-up

Posted Date: June 25th, 2020

DOI: https://doi.org/10.21203/rs.3.rs-37176/v1

License: (a) This work is licensed under a Creative Commons Attribution 4.0 International License. Read Full License 


\section{Abstract}

INTRODUCTION: Papillary renal cell carcinoma is a rare cancer and is the second most frequent histologic type among all renal cell carcinoma, accounting for up to $15 \%$. Patients with type 1 PRCC are diagnosed at a lower stage and present a lower nuclear grade compared to type 2.

CASE PRESENTATION: A 72-year-old man underwent a right radical nephrectomy 7 years ago for a $10 \mathrm{~cm}$ mesorenal mass with a final histopathological diagnosis of a papillary renal cell carcinoma type 1 pT2a with negative surgical margins.

Five years after the surgery, computed tomography (CT) scan imaging showed the presence of multiple masses suspicious for node recurrences disease localized in the renal lodge, in the inter-aorto-caval space, at the iliac vessel bifurcation and right common iliac vessels. Patient underwent a robotic retroperitoneal lymphadenectomy. The operative time was $114 \mathrm{~min}$, estimated blood loss $200 \mathrm{ml}$; length of hospital stay 4 days. The abdominal drainage was removed at first post-operative day. No perioperative complications. The removed lesions confirmed on histopathological examination the recurrence of type I papillary renal cancer at: renal lodge, inter-aorto-caval space, iliac bifurcation, common iliac lymph nodes. No further recurrences on surveillance imaging 24 months after his procedure.

DISCUSSION AND CONCLUSION: We present the first description of minimally invasive surgical excision for a papillary type I renal cancer nodal recurrence and renal fossa recurrence.

Our present study shows that patients treated with surgical excision for isolated RPLN recurrences may afford select patient durable cancer control.

The robotic approach can be offered as an effective modality of treatment in this rare case of type I papillary renal cancer metastases.

The extent of resection, as well as the optimal integration of surgery and systemic therapy, remain to be determined in this setting.

\section{Introduction}

Papillary renal cell carcinoma (PRCC) is the second most frequent histologic type among all renal cell carcinoma, accounting for up to 15\% [1] and it is subclassified into two groups, type 1 and type 2 , depending on nuclear features and growth pattern characteristics [2, 3].

Patients with type 1 PRCC are diagnosed at a lower stage and present a lower nuclear grade compared to type $2[4,5]$. In addition, type 1 described a higher cancer-specific survival and a reduced association with inferior vena cava thrombus compared to type $2[6,7]$. 
We presented a case of a papillary type 1 renal cell carcinoma lymph nodes recurrence after five years of follow up in a patient who underwent a totally robotic retroperitoneal lymphadenectomy. As our knowledge, this is the one of the few cases in literature that describes a papillary type 1 recurrence after such a long follow-up period.

\section{Case Presentation}

A 72-year-old man underwent a right radical nephrectomy 7 years ago for a $10 \mathrm{~cm}$ mesorenal mass with a final histopathological diagnosis of a papillary renal cell carcinoma type 1 pT2a with negative surgical margins.

Five years after the surgery, computed tomography (CT) scan imaging showed the presence of multiple masses suspicious for node recurrences disease localized in the renal lodge, in the inter-aorto-caval space, at the iliac vessels bifurcation and right common iliac vessels. Positron emission tomography CT confirmed abnormal uptake in the same lesions with a maximal standardized uptake value of 3.2.

Patient underwent a robot-assisted retroperitoneal lymphadenectomy with the enucleation of the perirenal peritoneum.

Patient was put on a left flank side position. The da Vinci Surgical System Si (Intuitive Surgical, Sunnyvale, CA) was used for the operation. A three-arm robotic approach was used (12 mm camera port located $4 \mathrm{~cm}$ lateral to the umbilicus; $8 \mathrm{~mm}$ port in the epigastrium for robotic arm \#1; $8 \mathrm{~mm}$ port in the right lateral mid abdomen for robotic arm \#2; and a $12 \mathrm{~mm}$ and $5 \mathrm{~mm}$ port inferior and respectively lateral and medial to the camera port for the assistant). A 30-degree down lens is utilized lens during the whole procedure.

We routinely use the Air Seal (Conmed; Utica, New York, USA) insufflation device is used to maintain pneumoperitoneum at $12 \mathrm{mmHg}$. Robotic monopolar scissors and Maryland bipolar were primarily used with a robotic prograsp for retraction.

After robotic lysis of adhesions, the procedure started with the excision of the right common iliac lymph nodes and then moving to the iliac bifurcation lymph nodes. Therefore, surgery continued with the access to the interaortocaval space, with the excision of a $4 \mathrm{~cm}$ mass where the IVC was carefully defined with meticulous dissection to prevent inadvertent violation (Fig. 1). At last, the procedure continued with the excision of retroperitoneal fat of the right renal fossa and of a $2 \mathrm{~cm}$ peritoneal nodal recurrence. Each anatomical nodal package is sent for individual pathological evaluation to allow node mapping.

The operative time was $114 \mathrm{~min}$, estimated blood loss $200 \mathrm{ml}$. The patient ambulated the same day as surgery, with diet advanced as tolerated. The abdominal drainage was removed at first post-operative day. Length of hospital stay was 3 days. No perioperative complications occurred.

The involved common iliac node measured $5 \mathrm{~cm}$ on final pathology, the iliac bifurcation node measured $3.5 \mathrm{~cm}$, the interaortocaval node measured $4.5 \mathrm{~cm}$, the renal fossa fat measured $6 \mathrm{~cm}$ and the peritoneal 
node measured $3 \mathrm{~cm}$, all samples with negative margin of resection.

At hematoxylin and eosin staining, fibrous connective tissue with multiple foci of a proliferation consisting of numerous papillary projections with fibrovascular axis replete with frothy macrophages and delimited by a single layer of small cellular elements, with ovoid nucleus and inconspicuous nucleolus and weakly basophilic cytoplasm (Fig. 2).

The removed lesions confirmed on histopathological examination the recurrence of type I papillary renal cancer in all the nodal packages.

Three months after surgery, patient was treated with systemic immunotherapy starting Sunitinib which was stopped one month later following the onset of general weakness associated to nausea and vomiting. Patient is still under follow-up and had no further recurrences on surveillance imaging 24 months after his procedure.

\section{Discussion And Conclusion}

PRCC has a better prognosis after surgical treatment when compared to clear cell RCC and most of cases is linked to a lower stage and describe a lower risk of cancer-specific and overall mortality [1, 8-9].

PRCC is characterized by a significant heterogeneity observed in both histologic level and clinical evolution, with the postulation of two morphologically different entities that are linked to cytogenetic diversity [2-3]. Type 1 is constituted by small cells with basophilic cytoplasm, while type 2 by larger cells with eosinophilic cytoplasm. The two histologic subtypes lead to a different rate of recurrence and survival, where stage and lymph node involvement represent an important predictor of relapse.

Several studies identify the correlation between these parameters and both recurrence and survival. Margulis et al. studied 245 patients surgically treated for PRCC describing both tumor stage and lymph node involvement as independent predictors of disease-specific mortality [10].

Compared to clear cell tumors, PRCC is characterized by predisposition for regional lymph node spread with synchronous metastases at diagnosis [11]. These findings are well linked with tumors larger than $8 \mathrm{~cm}$ [12].

Ledezma et al studied 627 patients with PRCC undergoing surgery and observed that 48 (8\%) experienced relapse of which 10 out of 27 patients with papillary type 2 RCC exhibited metastatic disease in the lymph nodes, whereas most patients with type 1 PRCC (11/21) metastasized to the lungs [13].

According to Dekernion et al, the concomitant presence of local renal fossa recurrence in addition to a metastatic disease leads to a $40 \%$ of overall survival at 12 months [14]. On the contrary, the absence of further metastases, showed that surgery was statistically superior for cause specific survival in patients with solitary cancer [15]. 
Russell et al identified 50 patients who underwent resection of isolated retroperitoneal lymphadenectomy (RPLN) recurrence of RCC after nephrectomy. They found that those patients with a longer interval from nephrectomy to RPLN recurrence had significantly decreased risks of progression after resection, suggesting that this variable may be used in patient selection [16].

Open surgical management has been most extensively documented, but the feasibility of laparoscopic management with or without hand assistance has been described only on a limited basis.

We opted to take advantage of robotic instrumentation in relation to the unique nature of these cases with the possibility of dealing with challenging adhesions often encountered in re-operative procedures.

We present the first description of minimally invasive surgical excision for a papillary type I renal cancer nodal recurrence, as well as renal fossa recurrence.

Our present study shows that patients treated with surgical excision for isolated RPLN recurrences may experience durable PFS and CSS. The patient at his least follow-up (24 months) was studied with PET-CT scan that confirmed the absence of local and distant recurrences. The impact of adjuvant therapy for type 1 PRCC (such as tyrosine kinase inhibitors) is still under investigation in literature, and only few reports are on subtype 1 PRCC not allowing to conclude about the role of systemic therapy in this tumour. Furthermore, in our case the therapy was discontinued after only 30 days for the onset of adverse events.

Present data show that surgical resection of isolated RPLN recurrence from PRCC may afford select patients durable cancer control. In particular, those patients with a longer interval from nephrectomy to RPLN recurrence, had significantly decreased risks of progression after resection, suggesting that this variable may be used in patient selection. The extent of resection, as well as the optimal integration of surgery and systemic therapy, remain to be determined in this setting.

Thus, we recommend that, in the setting of isolated RPLN recurrence of RCC (in patients without precluding comorbidities), careful consideration with the patients and medical oncology colleagues be undertaken about the relative and individualized benefits of surgical resection, systemic therapy, and surveillance.

\section{Declarations}

\section{Funding}

None of the authors have any funding to disclose.

\section{Ethics declarations}

\section{Ethics approval and consent to participate}

All procedures in this study were approved by the Ethical Committee of the Department of Medico Surgical Science and Biotechnologies of Sapienza University of Rome. 


\section{Consent for publication}

Written informed consent was obtained from the patient for the publication of this case report and any accompanying images. A copy of the written consent is available for review by the Editor-in-Chief of this journal.

\section{Competing interests}

The authors declare that they have no competing interests.

\section{Authors' contributions}

YAS, ALP, AF and AC analyzed the data, and wrote the paper. AF, ALP, VP, SA interpreted the results. YAS, ALP, CD and VP discussed analyses, interpretation, and presentation. AF, SA, LC, GV associated data collection and their interpretation.

All authors read and approved the manuscript.

\section{Acknowledgements}

Not applicable.

\section{References}

1. Steffens S, Janssen M, Roos FC. Incidence and long-term prognosis of papillary compared to clear cell renal cell carcinoma-a multicentre study. Eur J Cancer. 2012;48:2347-52.

2. Delahunt B, Eble JN. Papillary renal cell carcinoma: a clinicopathologic and immunohistochemical study of 105 tumors. Mod Pathol. 1997;10:537-44.

3. Shuch B, Amin A, Armstrong AJ, Eble JN, Ficarra V, Lopez-Bel-tran A, Martignoni G, Rini BI, Kutikov A. Understanding pathologic variants of renal cell carcinoma: distilling therapeutic opportunities from biologic complexity. Eur Urol. 2015;67:85-97.

4. Mejean A, Hopirtean V, Bazin JP. Prognostic fac- tors for the survival of patients with papillary renal cell carcinoma: meaning of histological typing and multifocality. J Urol. 2003;170:764-7.

5. Klatte T, Pantuck AJ, Said JW. Cytogenetic and molecular tumor profiling for type 1 and type 2 papillary renal cell carci-noma. Clin Cancer Res. 2009;15:1162-9.

6. Pignot $\mathrm{G}$, Elie $\mathrm{C}$, Conquy S. Survival analysis of 130 patients with papillary renal cell carcinoma: prognostic utility of type 1 and type 2 subclassification. Urology. 2007;69:230-5.

7. Kim KH, You D, Jeong IG. Type II papillary histology predicts poor outcome in patients with renal cell carcinoma and vena cava thrombus. BJU Int. 2012;110:673-8.

8. Keegan KA, Schupp CW, Chamie K. Histopathology of surgically treated renal cell carcinoma: survival differences by subtype and stage. J Urol. 2012;188:391-7. 
9. Pal SK, Nelson RA, Vogelzang N. Disease-specific survival in de novo metastatic renal cell carcinoma in the cytokine and targeted therapy era. PLoS ONE. 2013;8:e63341.

10. Margulis V, Tamboli P, Matin SF. Analysis of clinico- pathologic predictors of oncologic outcome provides insight into the natural history of surgically managed papillary renal cell car- cinoma. Cancer. 2008;112:1480-8.

11. Renshaw AA, Richie JP. Subtypes of renal cell carcinoma. Different onset and sites of metastatic Disease. Am J Clin Pathol. 1999;111:539-43.

12. Mai KT, Landry DC, Robertson SJ. A comparative study of metastatic renal cell carcinoma with correlation to subtype and primary tumor. Pathol Res Pract. 2001;197:671-5.

13. Ledezma RA, Negron E, Paner GP, et al. Clinically localized type 1 and 2 papillary renal cell carcinomas have similar survival outcomes following surgery. World J Urol. 2016;34:687-93.

14. Dekernion JB, Ramming KP, Smith RB. The natural history of metastatic renal cell carcinoma: a computer analysis. J Urol. 1978;120:148-52.

15. Itano NB, Blute ML, Spotts B, et al. Outcome of isolated renal cell carcinoma fossa recurrence after nephrectomy. J Urol. 2000;164:322-5.

16. Russell CM, Lue K, Fisher J, Kassouf W. Oncological control associated with surgical resection of isolated retroperitoneal lymph node recurrence of renal cell carcinoma. BJU Jun. 2016;117(6B):E606.

17. Ronnen EA, Kondagunta GV, Ishill N, et al. Treatment outcome for metastatic papillary renal cell carcinoma patients. Cancer. 2006;107(11):2617-21.

\section{Figures}

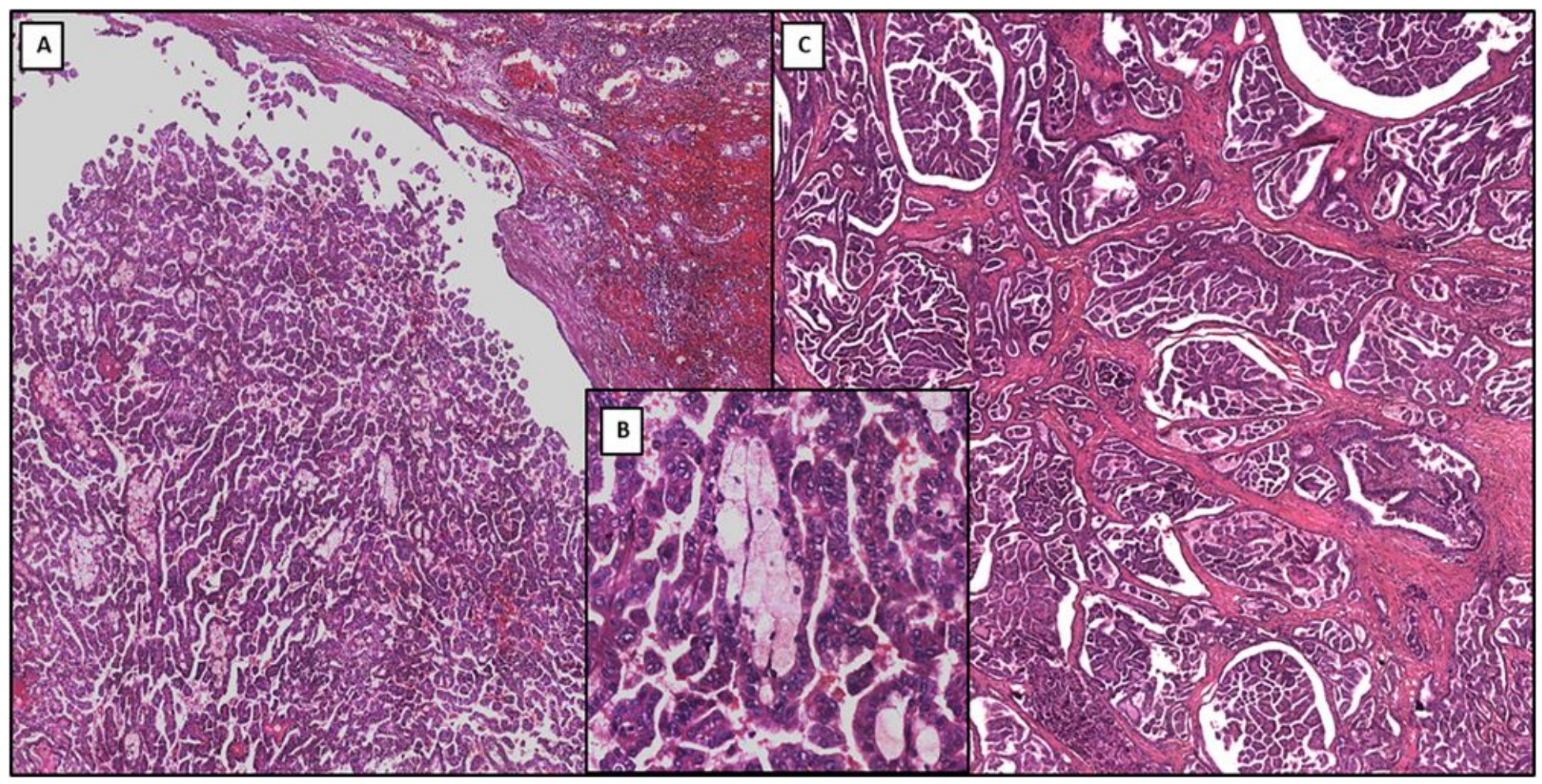


Figure 1

(A) Low-power photomicrograph showing primary papillary renal cell carcinoma (original magnification $4 \mathrm{x})$; (B) Medium-power photomicrograph showing the detailed structure of primary papillary renal cell carcinoma: papillae formed by delicate fibrovascular cores that contain foamy macrophages (original magnification 20x); (C) Low-power photomicrograph showing metastatic papillary renal cell carcinoma (original magnification $4 \mathrm{x}$ ).

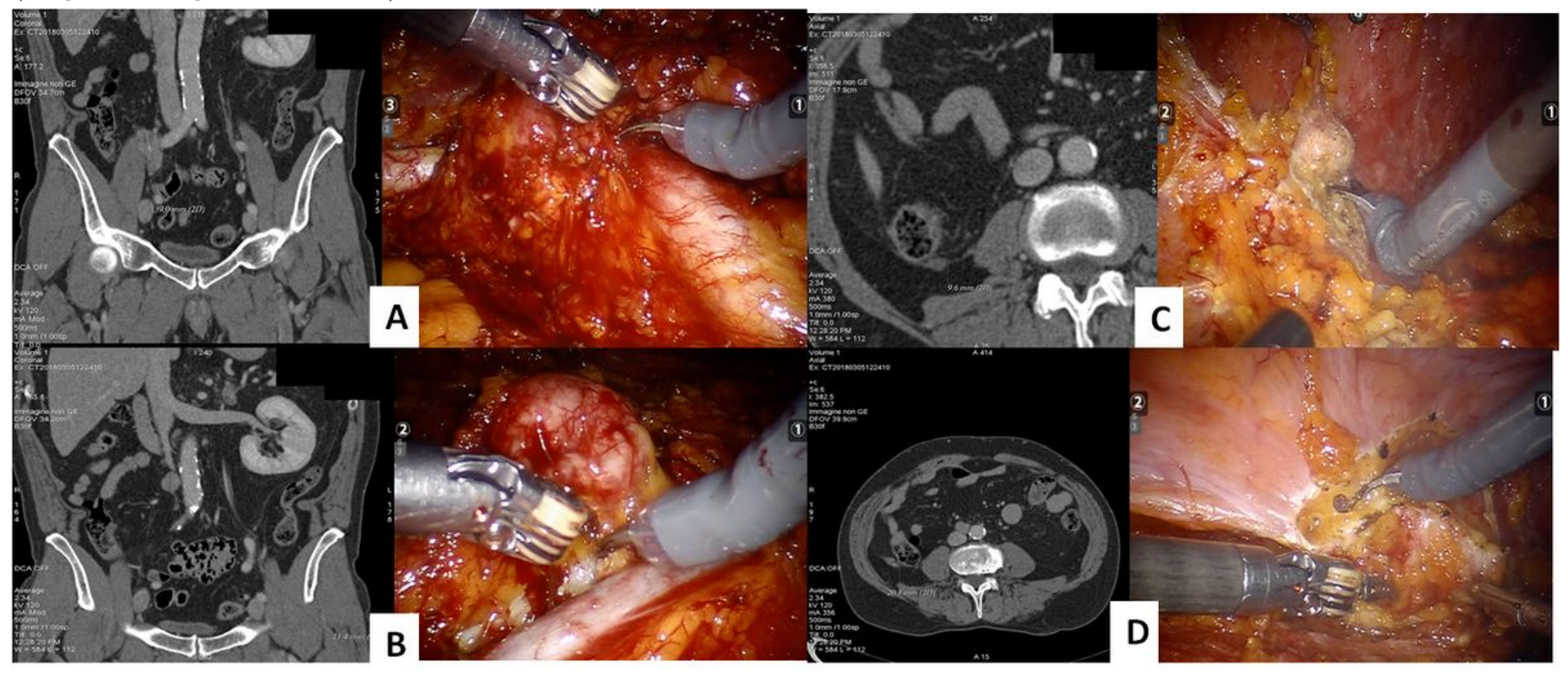

\section{Figure 2}

CT scan and intraoperative image of the: iliac bifurcation lymph node recurrence $(A)$; the interaortocaval space lymph node recurrence $(B)$; the renal fossa recurrence $(C)$; the peritoneal recurrence (D) 